\title{
CENTRAL MACULAR THICKNESS AFTER COMBINED THERAPY OF BEVACIZUMAB INTRAVITREAL INJECTION AND TOPICAL DICLOFENAC COMPARED WITH BEVACIZUMAB INTRAVITREAL INJECTION IN DIABETIC MACULAR EDEMA
}

\author{
Melvina Nidya Sandra ${ }^{1}$, Yumni Shabrina ${ }^{1}$, Tri Wahyu Widayanti ${ }^{1}$, Retno Ekantini ${ }^{1}$, Agus Supartoto ${ }^{1}$, Muhammad \\ Bayu Sasongko ${ }^{1}$, Supanji ${ }^{1}$ \\ ${ }^{1}$ Department of Ophthalmology Universitas Gadjah Mada - Sardjito Hospital
}

\begin{abstract}
Introduction: To evaluate whether the combination of diclofenac eye drops and bevacizumab intravitreal injection would provide additional benefits over bevacizumab only in the treatment of naïve diabetic macular edema (DME).

Methods: A total of 43 patients were randomized into two groups to receive combination treatment with bevacizumab intravitreal injection and topical diclofenac (group 1) or bevacizumab intravitreal injection only (group 2). Group 1 patients received single bevacizumab intravitreal injection and got self-administered diclofenac eye drop four times daily for one month. Group 2 patients received single bevacizumab intravitreal injection alone. Outcome data were achieved from patient visits at primary visit and at 1 month after bevacizumab intravitreal injection. All patients underwent measurement of best corrected visual acuity (BCVA), a complete eye examination, and measurement of central macular thickness (CMT).
\end{abstract}

Result: The mean reduction in CMT in the group 1 was $130.42 \pm 32.57 \mu \mathrm{m}(p<0.01)$, while in the group 2 the reduction was $141.38 \pm 45.27 \mu \mathrm{m}(p<0.01)$, there is no significant difference between the two groups $(p=0.866)$. The mean improvement of BCVA was $0.32 \pm 0.10 \mathrm{log}$ Mar in the combination group and $0.26 \pm 0.12$ in group 2 , there is no significant difference between the two groups $(p=0.691)$. There was no adverse ocular event in the two groups.

Conclusion: In patients with naïve DME, adding diclofenac eye drop as adjuvant of bevacizumab intravitreal injection are less likely to have a meaningful effect on reducing the central macular thickness.

\begin{abstract}
Keywords: Diabetic macular edema, NSAID, diclofenac, anti-VEGF, bevacizumab, central macular thickness Cite This Article: HARYANTO, Supanji; SANDRA, Melvina Nidya. CENTRAL MACULAR THICKNESS AFTER COMBINED THERAPY OF BEVACIZUMAB INTRAVITREAL INJECTION AND TOPICAL DICLOFENAC COMPARED WITH BEVACIZUMAB INTRAVITREAL INJECTION ALONE IN DIABETIC MACULAR EDEMA. International Journal of Retina, [S.I.], v. 4, n. 2, p. 106, sep. 2021. ISSN 2614-8536. Available at: <https://www.ijretina.com/index.php/ijretina/article/view/164>.doi: https://doi.org/10.35479/ijretina.2021.v ol004.iss002.164.
\end{abstract}

\begin{tabular}{l} 
Correspondence to: \\
Supanji, \\
Ophthalmology Department \\
Universitas Gadjah Mada, \\
supanji@ugm.ac.id \\
\hline
\end{tabular}

\section{INTRODUCTION}

Diabetic macular edema (DME) can appear at various stages of diabetic retinopathy. DME has a prevalence of $6.8 \%$ of patients with diabetes mellitus. ${ }^{(1)}$ DME is the most common cause of permanent visual loss in patients with diabetes. Intravitreal anti-VEGF has been widely used as therapy in DME but $30 \%$ of patients are resistant to this therapy ${ }^{(2)}$ It can be thought that there are other mechanisms involved in the pathogenesis of $D M E$, one of which is inflammation

(3) Low-grade subclinical inflammation are responsible for the 
development of DME. The expression of interleukin-6 (IL-6) and cyclooxygenase-2 are upregulated, therefore vascular permeability deteriorates.

Corticosteroids are an effective therapy because of their ability to fight inflammatory factors that contribute to DME but have many unwanted side effects such as cataracts and increased intraocular pressure. (4) In order to overcome this issue, alternative NSAIDs can be used as a strategy to get an anti-inflammatory effect without promoting side effects. Topical NSAIDs are widely used in the prevention and therapy in the case of cystoid macular edema after cataract extraction. ${ }^{(5)}$ The use of topical NSAIDs combined with anti-VEGF has been shown to reduce retinal thickness in pseudophakic cystoid macular edema. ${ }^{(6)}$ However, the effectiveness of the combination of topical NSAIDs and anti-VEGF in DME is not well known.

In this study, we prospectively evaluated whether the combination of diclofenac eye drops four times a day and intravitreal bevacizumab injections would provide additional benefits over bevacizumab only in patients with naïve DME.

\section{METHODS}

Data for this study were collected using a doubleblind randomized controlled trial. The study included 43 patients with naïve DME. All patients were enrolled consecutively and randomized to receive combination treatment with bevacizumab intravitreal injection and topical diclofenac (group 1) or bevacizumab intravitreal injection (group 2). ${ }^{(7)}$

All patients received single bevacizumab intravitreal injection. Patients were self-administered with topical diclofenac four times a day for one month and the participants were evaluated.
Subjects were qualified if the following criteria were met: (1) patients diagnosed with DME by a retinal specialist; (2) age > 18 years; (3) never had corticosteroid/NSAIDs or prostaglandin analog therapy, anti-VEGF, and pan-retinal photocoagulation laser. Exclusion criteria were as follows: (1) patients with significant media opacity; (2) underwent intraocular surgery during the study period; (3) having anterior segment infection or inflammation.

The following assessments were performed by a blinded examiner at every visit: (1) measurement of BCVA; (2) assessment of adverse ocular event (e.g, infection, inflammation, endophthalmitis); (3) fully dilated ophthalmic examination; (4) CMT measurement by OCT. Statistics were performed using the Wilcoxon test for changes in BCVA and CMT within the group. Between subgroups, MannWhitney analysis was used. Statistical analyses were performed using SPSS software.

\section{RESULTS}

A total of 43 patients met the study criteria and randomly assigned to either group 1 or group 2 . One patient in group 1 drops out because the patient passed away. The table below illustrates the baseline characteristics of the participant group (group 1 , bevacizumab and diclofenac; group 2, bevacizumab).

Table 1. Baseline characteristics

\begin{tabular}{llll}
\hline & $\begin{array}{l}\text { Group 1 } \\
(\mathrm{n}=22)\end{array}$ & $\begin{array}{l}\text { Group 2 } \\
(\mathrm{n}=21)\end{array}$ & $\mathrm{p}$ \\
\hline Age (years, mean \pm SD) & $55.76 \pm 1.51$ & $56.83 \pm 1.64$ & 0.522 \\
\hline Sex $(\mathrm{n}, \%)$ & & & \\
\hline Male & $9(38.1 \%)$ & $5(31.2 \%)$ & 0.284 \\
\hline Female & $13(61.9 \%)$ & $16(68.7 \%)$ & \\
\hline CMT $(\mu \mathrm{m})$ & $466.90 \pm 45.81$ & $437.50 \pm 37.11$ & 0.355 \\
\hline BCVA (log Mar) & $1.16 \pm 0.15$ & $0.94 \pm 0.16$ & 0.349 \\
\hline Intraocular pressure & $16.19 \pm 0.98$ & $16.61 \pm 1.01$ & 0.791 \\
(mmHg) & & & \\
\hline
\end{tabular}


As can be seen from the table below (table 2), the baseline means BCVA were $1.16 \pm 0.15 \log$ Mar in group 1 and $0.94 \pm 0.16 \log$ Mar in group 2. At 1 month follow up the mean BCVA group 1 were improved significantly to $0.83 \pm 0.12(p=0.005)$ while in group 2 the improvement was not statistically significant $(p=0.052)$. There was no statistically significant difference between the two treatment arms $(p=0.691)$.

Table 2. BCVA and CMT between two groups.

\begin{tabular}{clll}
\hline & Group 1 & Group 2 & $\begin{array}{c}\mathrm{p} \\
\text { (between } \\
\text { group) }\end{array}$ \\
\hline BCVA (log Mar) & & & \\
\hline Baseline & $1.16 \pm 0.15$ & $0.94 \pm 0.16$ & \\
\hline 1 month & $0.83 \pm 0.12$ & $0.67 \pm 0.15$ & \\
\hline Difference & $0.32 \pm 0.10$ & $0.26 \pm 0.12$ & 0.691 \\
\hline $\mathrm{p}$ (within group) & 0.005 & 0.052 & \\
\hline CMT ( $\mu$ m) & & & \\
\hline Baseline & $466.90 \pm 45.81$ & $437.50 \pm 37.11$ & \\
\hline 1 month & $336.47 \pm 24.83$ & $296.11 \pm 19.96$ & \\
\hline Difference & $130.42 \pm 32.57$ & $141.38 \pm 45.27$ & 0.866 \\
\hline p (within group) & 0.000 & 0.002 & \\
\hline
\end{tabular}

Group 1, bevacizumab and diclofenac; group 2, bevacizumab

(infection, inflammation, and endophthalmitis) during the study period.

From this data, it can be seen that CMT was significantly reduced in group 1 and group 2 . In group 1 the mean reduction from baseline was $130.42 \pm 32.57 \mu \mathrm{m}(p=0.000)$ while in group 2 was $141.38 \pm 45.27 \mu \mathrm{m} \quad(p=0.002)$. There was no statistically significant difference between the two treatment arms $(p=0.866)$. There was no ocular adverse effect in both groups.

\section{DISCUSSION}

The result of this study suggests that there is likely no benefit in the addition of topical diclofenac in naïve DME. However, this outcome does not support the previous research where the combination of bevacizumab intravitreal injection and diclofenac intravitreal injection reduced CMT more than bevacizumab intravitreal injection only in patient with naïve diabetic macular edema. ${ }^{(8)}$ A possible explanation for this might be because the NSAIDs used were delivered directly to vitreous. Another study conducted by Warren showed greater retinal thickness reduction in patients who received combination of bevacizumab and intravitreal dexamethasone intravitreal injection with topical NSAID (nepafenac or bromfenac or ketorolac) compared to bevacizumab and dexamethasone intravitreal injection in patients with refractory diabetic macular edema. The bromfenac and nepafenac group required fewest number of additional intravitreal injection. ${ }^{(9)}$ The differences between this study and the study conducted by Warren are the naïve/refractory status of the diabetic macular edema and the NSAID used of this study were different. Compared with diclofenac, amfenac, and ketorolac, bromfenac is reported to be a 3 to 18 times more potent inhibitor of COX-2. ${ }^{(10)} \mathrm{COX}-2$ is thought to be primarily responsible for inflammation, and therefore the anti-inflammatory actions of NSAIDs are assumed to relate to their ability to inhibit this isoform. ${ }^{(5)}$ In a study comparing the efficacy of bromfenac, nepafenac, and diclofenac founded that bromfenac was more effective in preventing cystoid macular edema after cataract surgery than nepafenac. However, nepafenac is more effective in reducing inflammation than bromfenac. Nepafenac and bromfenac were more effective at reducing macular thickness in post-cataract macular edema compared to diclofenac. ${ }^{(11)}$

A study conducted by Friedman et al founded that administration of topical nepafenac two times a day have no beneficial effect on retinal thickening and visual acuity outcome. ${ }^{(12)}$ This is contrary to reports showing a beneficial effect of nepafenac on macular edema in patients with diabetes. The difference might be caused by the different mechanism of macular edema, especially macular edema in the setting of cataract surgery. ${ }^{(13)}$ As with any study with topical eye drop treatment, patients' compliance can affect the outcome. 
VEGF is a potent vasopermeability factor that has been targeted extensively in DME. Compared with non-diabetic eyes, the VEGF levels are significantly increased in vitreous of DME patients. ${ }^{(14)}$ VEGF induced leukostasis in the retina, enhancing vascular permeability and capillary non-perfusion. Despite of being mostly a vasogenic factor, VEGF also trigger inflammation. VEGF induced ICAM-1 expression, leukocyte adhesion, and monocyte migration. ${ }^{(15)}$ The inflammatory process is also initiated by microglial cells, together with Muller cells and astrocytes, escalate this response and low-grade inflammation is preserved by the production of interleukin 6 (IL-6) and interleukin 8 (IL-8). IL- 6 changes the function of astrocytes, thus breaking the inner blood-retinal barrier. ${ }^{(16)}$ Currently, the first line treatment in centerinvolving DME were anti-VEGF agents. However, despite the treatment, $40 \%$ of DME eyes endured persistent macular edema (PME) after 6 monthly injections, and $32 \%$ of DME eyes had concomitant visual loss based on the results from Protocol I and Protocol T. ${ }^{(17,18)}$

Several factors influence the prognosis of successful therapy in DME including the presence of wrinkled epiretinal membrane (ERM), presence of serous retinal detachment, disruption of external limiting membrane, hyper-reflective retinal spots, disruption of ellipsoid zone and the disorganization of inner retinal layers.

Increased CMT after treatment also considered predictor of poor response to treatment. ${ }^{(19,20)}$ The limitation of this study were short follow up and the diagnostic criteria for macular edema were only based on the CMT despite the presence of hard exudate and macular ischemia, both of which could affect the results of this study.

\section{CONCLUSIONS}

The results of this study suggest that there is likely no benefit of adding diclofenac eye drop as an adjuvant of bevacizumab intravitreal injection in reducing CMT in patients with naïve DME. Further longer studies, which take presence of hard exudate and macular ischemia into account are necessary to establish whether or not adding diclofenac as an adjuvant may be of long-term benefit in the treatment of naïve DME.

\section{REFERENCES}

1. Yau JW, Rogers SL, Kawasaki R, Lamoureux EL, Kowalski JW, Bek T, et al. Global prevalence and major risk factors of diabetic retinopathy. Diabetes Care. 2012;35(3):55664.

2. Wells JA, Glassman AR, Ayala AR, Jampol LM, Aiello LP, Antoszyk AN, et al. Aflibercept, bevacizumab, or ranibizumab for diabetic macular edema. The New England journal of medicine. 2015;372(13):1193-203.

3. Funatsu $H$, Yamashita $H$, Ikeda $T$, Mimura $T$, Eguchi S, Hori S. Vitreous levels of interleukin- 6 and vascular endothelial growth factor are related to diabetic macular edema. Ophthalmology. 2003;110(9):1690-6.

4. Ohira A, Hara K, Jóhannesson G, Tanito $M$, Ásgrímsdóttir GM, Lund SH, et al. Topical dexamethasone $\gamma$-cyclodextrin nanoparticle eye drops increase visual acuity and decrease macular thickness in diabetic macular oedema. Acta Ophthalmol (Copenh). 2015;93(7):610-5.

5. Kim SJ, Flach AJ, Jampol LM. Nonsteroidal anti-inflammatory drugs in ophthalmology. Surv Ophthalmol. 2010;55(2):108-33.

6. Warren KA, Bahrani H, Fox JE. NSAIDs in combination therapy for the treatment of chronic pseudophakic cystoid macular edema. Retina. 2010;30(2):260-6.

7. Sandra MN, Widayanti TW, Ekantini R, Supartoto A, Sasongko MB, Haryanto S. Changes in central macular thickness after combined therapy of bevacizumab intravitreal injection and topical diclofenac compared with bevacizumab intravitreal injection in diabetic macular edema. Thesis. 2021. 
8. Ghanbari $\mathrm{H}$, Kianersi F, Sonbolestan SA, Abtahi M-A, Akbari M, Abtahi Z-A, et al. Intravitreal Diclofenac plus Bevacizumab versus Bevacizumab alone in treatment-naive diabetic macular edema: a randomized double-blind clinical trial. Int Ophthalmol. 2017;37(4):867-74.

9. Warren KA. Combination therapy for diffuse macular edema (DME). Paper Presented at the Retina Society and the Societa Italiana della Retina meeting. 2011.

10. Ahuja M, Dhake AS, Sharma SK, Majumdar DKJTAj. Topical ocular delivery of NSAIDs. 2008;10(2):229-41.

11. Capote $A M C$, Soto $M L$, Ruiz FR, Peláez EC, Vazquez AG, OftaCosta G, et al. Comparative study of the efficacy and safety of bromfenac, nepafenac and diclofenac sodium for the prevention of cystoid macular edema after phacoemulsification. 2018;11(7):1210.

12. Friedman $\mathrm{SM}$, Almukhtar $\mathrm{TH}$, Baker $\mathrm{CW}$, Glassman AR, Elman MJ, Bressler NM, et al. Topical nepafenec in eyes with non-central diabetic macular edema. 2015;35(5):944.

13. Almeida DR, Khan Z, Xing L, Bakar SN, Rahim $K$, Urton $T$, et al. Prophylactic nepafenac and ketorolac versus placebo in preventing postoperative macular edema after uneventful phacoemulsification. 2012;38(9):1537-43.

14. Funatsu $H$, Noma $H$, Mimura $T$, Eguchi $S$, Hori SJO. Association of vitreous inflammatory factors with diabetic macular edema. 2009;116(1):73-9.
15. Zur D, Iglicki M, Loewenstein AJOr. The role of steroids in the management of diabetic macular edema. 2019;62(4):231-6.

16. Romero-Aroca $P$, Baget-Bernaldiz M, ParejaRios A, Lopez-Galvez M, Navarro-Gil R, Verges RJJodr. Diabetic macular edema pathophysiology: vasogenic versus inflammatory. 2016;2016.

17. Elman MJ, Aiello LP, Beck RW, Bressler NM, Bressler SB, Edwards AR, et al. Randomized trial evaluating ranibizumab plus prompt or deferred laser or triamcinolone plus prompt laser for diabetic macular edema. 2010;117(6):1064-77. e35.

18. Wells JA, Glassman AR, Ayala AR, Jampol LM, Bressler NM, Bressler SB, et al. Aflibercept, bevacizumab, or ranibizumab for diabetic macular edema: two-year results from a comparative effectiveness randomized clinical trial. 2016;123(6):1351-9.

19. Ashraf $M$, Souka A, Adelman RJBJoO. Predicting outcomes to anti-vascular endothelial growth factor (VEGF) therapy in diabetic macular oedema: a review of the literature. 2016;100(12):1596-604.

20. Parravano $M$, Costanzo E, Querques GJAd. Profile of non-responder and late responder patients treated for diabetic macular edema: systemic and ocular factors. 2020:1-11.

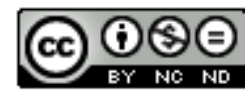

This work licensed under Creative Commons Attribution 